finds it tolerable, whereas she often finds an identical preparation given for symptoms unacceptable. So it is with hysterectomy.

${ }^{1}$ Muldoon, M J, British Medical fournal, 1972, 1, 84.

${ }^{2}$ Chandler, C J, 1977, in preparation.

${ }^{3}$ Burchell, R C, American Fournal of Obstetrics and Gynecology, 1977, 127, 113.

'Haynes, D M, and Wolfe, W M, American fournal of Obstetrics and Gynecology, 1970, 106, 1044.

5 Little, W A, American fournal of Obstetrics and Gynecology, 1975, 123, 12.

6 Wheeless, C R Jr, American fournal of Obstetrics and Gynecology, 1975, 122,872 .

${ }^{7}$ Ballard, C A, American fournal of Obstetrics and Gynecology, 1974, 118 891.

8 Winston, R M L, British Medical fournal, 1977, 2, 305.

9 Slack, W V, Lancet, 1977, 2, 240.

\section{Committee on the Review of Medicines: testing the golden oldies}

Once the Medicines Act came into effect in 1971, manufacturers wanting to license new drugs had to provide evidence of their safety, quality, and efficacy. Though some critics have suggested that the procedure has made for long delays, in general it seems to have worked satisfactorily enough. What, however, of the drugs already on the market (and licensed automatically) in 1971 ? How well tested were they? Were the claims being made by their makers justified by evidence that the Committee on Safety of Medicines would have considered acceptable if they had been new products? Two years ag, the Medicines Division of the Department of Health began in attempt to answer these questions through the Herculean task of reviewing the 30000 products given licences as of righi when controls first came in.

In fact, the committee set up to carry out the review will not be looking at ll the individual products. Many are obsolete and some tizarre, and there is much overlapsix or eight licences may exist for the same drug manufactured by one company. Often, ho, a standard remedy is sold under many trade names. The total list includes some 10000 remedies of plant origin, mostly sold direct to the public by herbalists; some 4000 homoecpathic products; some 12000 "prescription fillers" (generic pinducts sold under the name of the active ingredient with no indications for use); some 1500 over-the-counter products; and only 4000-5000 proprietary prescription products listea in $M I M S$. For the prescription products the Committee on the Review of Medicines (CRM) is looking at evidence from clinical trials, adverse reaction reports, papers in scientific journals, and evidence from professional bodies in an attempt to agree uniform standards for specifying indications for the use of the drugs, their dosage, contraindications and warnings, and pharmaceutical standards. The licence holders whose drugs are under review are also being consulted and in some cases asked to provide additional information.

The first drugs to be examined in detail by the expert subcommittee set up under the CRM was the group of non-steroidal anti-inflammatory agents. This group of drugs was given priority because of their widespread use and the frequency of adverse reactions reported with this. The CRM's recommendations (published at $\mathrm{p}$ 757), deal with the mefenamic and flufenamic acids, indomethacin, ibuprofen, alclofenac, ketoprofen, fenoprofen, and naproxen. The conclusions will come as no great surprise, but some clinicians may be perplexed by the few indications listed under the different drugs. The indications approved are based on all the available evidence of efficacy reviewed by the subcommittee; only if good clinical evidence was available that an agent is effective in a given condition and is suitable for the treatment of this condition has it been included. All-embracing terms such as "allied conditions" and "related disorders" were not thought acceptable, and poorly defined indications such as "soft tissue rheumatism" were similarly unacceptable.

What are the practical implications of the changes? Any general practitioner or hospital doctor remains free to prescribe any drug that he considers to be in the best interests of his patient. The indications approved by the CRM are those proposed for the revised licences held by manufacturers who market the product. Data sheets and other published information will have to be in accordance with these recommendations, while the indications listed by a manufacturer will be limited to those based on clinical evidence considered and approved by the CRM. The same is true of contraindications, warnings, and precautions. For example, all the recommendations for "carboxylic acid" antirheumatic drugs are contraindicated in the presence of active peptic ulceration. Even so, only the doctor who is fully informed of the patient's clinical condition can decide whether he should or should not prescribe a particular antirheumatic drug in this group to someone with an active peptic ulcer. Only the clinician, too, can decide whether the potential therapeutic benefit outweighs the risk. The stated contraindications are not absolute but do indicate the presence of a serious risk.

So, while the recommendations break little new ground for the practising doctor, they exemplify the nature of the examination that expert committees will now be making of the thousands of drugs, old, familiar, and unfamiliar, in terms of indications, uses, dosage, and adverse reactions. Recommendations on drugs related to phenylbutazone, antigout agents, cytotoxic drugs, gold, and D-penicillamine and other potentially toxic drugs used in treating rheumatic diseases will be published shortly. Aspirin and other salicylates, paracetamol, codeine, and other widely used drugs-some of which are available to the public without prescription-are under active consideration by both the antirheumatic and analgesic subcommittees of the CRM. A review of psychotropic drugs will begin later this year. The long-term objectives of these reviews are to ensure that all drugs, whether prescribed by doctors or available directly to the public, are of adequate quality and are safe and effective for their recommended uses. Many illogical and poorly substantiated products will disappear, and the overall effect should be a more rational use of medicines by both the prescribing doctor and the general public.

\section{Deception by immunisation}

ASM News, the monthly bulletin of the American Society for Microbiology, is not usually a source of material of historical scientific interest. The issue of June 1977 is an exception. It contains two short feature articles, ${ }^{12}$ one on Pasteur and the other on a hitherto undisclosed secret of the second world war.

The first is written by Marie-Louise Hemphill, a daughter of Adrien Loir, Pasteur's nephew and assistant in 1882-8. It recounts Loir's recollections of Pasteur's life and work at 